\title{
Erratum to: A review of the system of rice intensification in China
}

\author{
Wei Wu • Norman Uphoff
}

Published online: 15 July 2015

(C) Springer International Publishing Switzerland 2015

\section{Erratum to: Plant Soil \\ DOI 10.1007/s11104-015-2440-6}

The published online paper unfortunately contained an error. The second author of the original publication (Baoluo Ma) should be removed from the author group for he did not participate significantly to the work.

The online version of the original article can be found at http://dx. doi.org/10.1007/s11104-015-2440-6.

W. Wu $(\bowtie)$

College of Agronomy, Northwest A\&F University, Yangling, Shaanxi 712100, China

e-mail:weiwu@nwsuaf.edu.cn

W. $\mathrm{Wu}$

Eastern Cereal and Oilseed Research Centre, Agriculture and Agri-Food Canada, 960 Carling Ave, Ottawa, ON K1A 0C6, Canada

N. Uphoff

SRI International Network and Resources Center (SRI-Rice),

Cornell University, Ithaca, NY 14853, USA 